\title{
Hue-Heat Hypothesis: A Step forward for a Holistic Approach to IEQ
}

\author{
Francesca Romana d'Ambrosio Alfano ${ }^{1}$, Laura Bellia ${ }^{2}$, Francesca Fragliasso ${ }^{2}$, Boris Igor Palella, ${ }^{2,}$, Giuseppe Riccio ${ }^{2}$. \\ ${ }^{1}$ DIIn Dipartimento di Ingegneria Industriale, Università degli Studi di Salerno, Via Giovanni Paolo II 132, 84048 Fisciano, Italy. \\ ${ }^{2}$ DII, Dipartimento di Ingegneria Industriale, Università degli Studi di Napoli Federico II, Piazzale Vincenzo Tecchio 80, 80125 Naples, \\ Italy
}

\begin{abstract}
For many years different human factors contributing to the IEQ have been studied separately. Concerning thermal perception, despite it is almost accepted that thermal comfort can be influenced by concomitant stimulation of non-tactile modalities, relatively few investigations have succeeded in delineating non-tactile stimulations as the visual ones. The hue-heat hypothesis is based on the idea that, when spectral irradiance pattern at the observer's eye shows a great amount of short wavelengths, the space is perceived as cooler. Conversely, when long wavelengths are predominant, the space is perceived as warmer. This means that operating on light characteristics could help in improving thermal comfort for the occupants with possible energy savings obtained by acting on the set-point temperature of HVAC systems. To verify this hypothesis, this paper will deal with a subjective investigation carried out in a special mechanically conditioned test room equipped with white-tuning LED sources. Investigated subjects have been exposed to two different light scenes consisting of warm $(3000 \mathrm{~K})$ and cool light sources $(6000 \mathrm{~K})$ at a fixed task illuminance value. Preliminary results seem to demonstrate that cool light is effective in shifting to cool the perceived thermal sensation with a general increase of people under neutral conditions.
\end{abstract}

\section{Introduction}

Only in recent years the application of the human factors' principles stated the need for rethinking the whole indoor built environment design [1] which should conjugate low energy costs with high IEQ [2] (as a result of thermal, acoustic and visual comfort, and indoor air quality) and sustainability requirements $[3,4]$.

IEQ strictly affects the overall building energy performances - as expressed again in the 2018/844 European Directive [5] - and it exhibits an antagonistic relationship with respect to the energy saving requirements. This means that the optimization of a single IEQ component should also consider possible antagonistic or synergic effects with the other IEQ components. This is also to reduce the onset of related illnesses and to optimize people's performance $[6,7]$.

Concerning thermal perception, despite it seems to be a common belief that thermal comfort can be influenced by concomitant stimulation of non-tactile modalities, relatively few investigations have succeeded in delineating non-tactile stimulations as the visual ones. The belief that colour can impart such effects as apparent warmth is widespread and ancient [8]. A popular hypothesis is that lights or surfaces, whose dominant frequencies are toward the red end of the visual spectrum, are "warm" and, those toward the blue end, are "cool". This is the concept of the hue-heat hypothesis $[8,9]$.

As stressed by Candas and Dufour [9] in a review devoted to the multisensory interactions on the thermal perception, several efforts have been made in the past to characterize the effect of the light colour on thermal comfort $[10,11]$, with experiments giving conflicting results. From this perspective, preliminary studies on the interaction between the light colour and the thermal sensation carried out by Fanger in the 70's sound almost astonishing. Despite he found in 16 subjects that a slightly lower ambient temperature $\left(0.4{ }^{\circ} \mathrm{C}\right.$ about $)$ was preferred in extreme red light compared to extreme blue light, he concluded that "did not seem to have any practical significance on man's thermal comfort" [10].

In addition, it is still unclear whether the colour of light affects the thermal sensation only under microclimatic conditions close to thermal neutrality as recently investigated by Toftum et al. [12]. Particularly, on a sample of 44 subjects (16 females) exposed to different lighting scenarios by operating on the ColourCorrelated Temperature (CCT) of LED sources at three levels of operative temperature $\left(19,22\right.$ and $\left.27^{\circ} \mathrm{C}\right)$, they concluded that CCT was associated with thermal sensation at the thermally neutral condition, but not when subjects felt slightly cool or slightly warm.

As also remarked by Huebner et al. [13] and by Wang et al. [14] in two more recent papers, existing research is ambiguous regarding the association between coloured light/indoor surfaces and thermal perception. In addition, the different methodologies and protocols adopted in different researches complicate the comparability between studies and the ability to draw final conclusions [13]. This is especially true because previous studies also suffered from methodological

\footnotetext{
* Corresponding author: palella@unina.it
} 
issues, such as insufficient control of illuminance levels, microclimatic parameters according to the Standards in the field and other factors affecting thermal comfort [14].

To verify the hue-heat hypothesis, this investigation will be focused on the analysis of preliminary results obtained by a combined microclimatic and subjective investigation carried out in a special mechanically conditioned test room provided with white-tuning LED sources under winter conditions and with two different light scenes.

\section{Methods}

\subsection{Test room lighting characterization}

Tests were performed in the Photometry and Lighting Laboratory of the Department of Industrial Engineering of the University of Naples Federico II (Italy). It is an Lshaped room composed of two different rectangular parts. The wider space (see figure 1 on the top) is equipped with a false-ceiling, where different light sources are installed. Among these sources there are the two recessed LED luminaires used for the experiment.

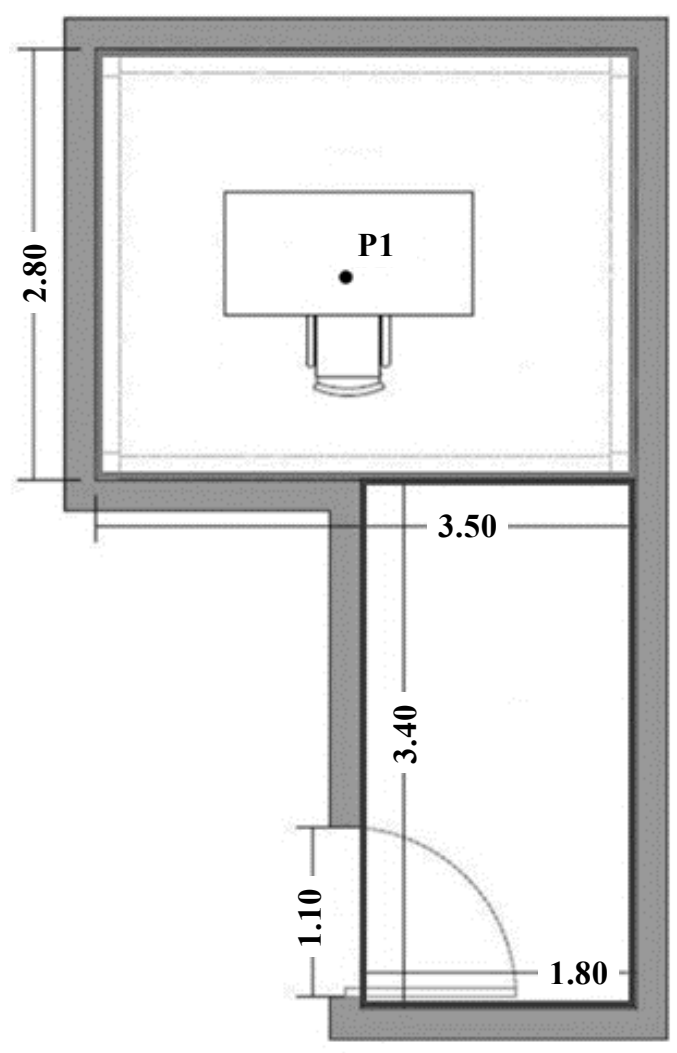

Fig. 1. Measured plan of the test-room.

This area is a neutral environment: three white curtains cover the perimeter walls and another one, once closed, divides the two parts of the room. A desk and a chair are here placed. In the smaller space (see figure 1 on the bottom) there is the DALI (Digital Addressable Lighting Interface) control unit necessary to manage the luminaires. It consists in a touch panel allowing easily setting different light scenes, by varying luminous flux emission of luminaires and their Correlated Colour Temperature (CCT).

LEDs used in this investigation were white-tuning ones, which allow to change CCT in the range $3000 \mathrm{~K}$ $6000 \mathrm{~K}$. According to the technical sheet provided by the manufacturer, luminaires characteristics are the following: luminous flux $=4280 \mathrm{~lm}$, power $=51 \mathrm{~W}$, Color Rendering Index $(\mathrm{CRI})>80$. For the experiment two light scenes were set: Scene 1 characterized by 3000 K CCT and Scene 2 characterized by $6000 \mathrm{~K} \mathrm{CCT.}$ Figure 2 reports normalized spectral power distributions of the luminaires when CCT is set at $3000 \mathrm{~K}$ and $6000 \mathrm{~K}$ respectively. They were measured by means of a Konica Minolta CS-2000 spectroradiometer.

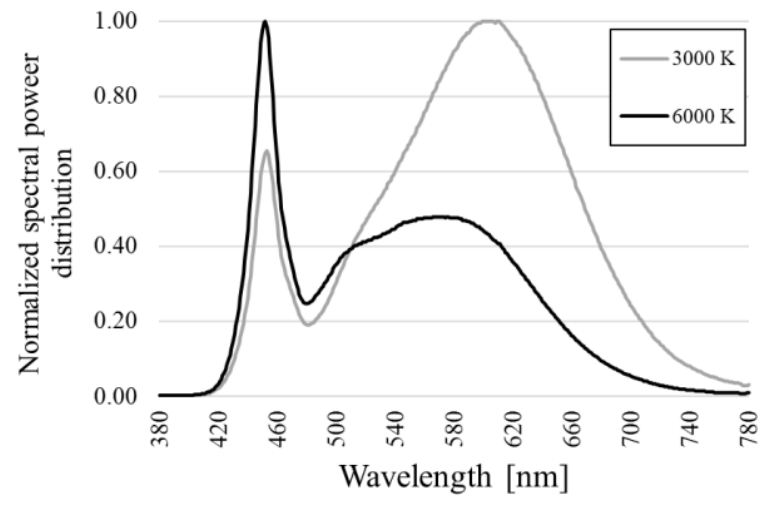

Fig. 2. LED normalized spectral power distribution.

For both CCTs, luminaires luminous flux was regulated so that the corresponding illuminance at the work-plane was equal to about $300 \mathrm{~lx}$ (consistently with a reading task [15]). To verify that, the illuminance was measured at the point P1 (see Figure 1) by means of a Konica Minolta T-10A luxmeter.

\subsection{Test-room microclimatic characterization}

The microclimatic characterization of the test room has been carried out by measuring all physical parameters affecting the thermal sensation (global and local) by means of a special Comfort Data Logger INNOVA 1221 provided with sensors for the air temperature, the plane radiant temperatures, the air velocity, the dew point and the floor temperature. In addition, three HOBO U12 Temp/RH/2 sensors for the measurement of air temperature and relative humidity have been used. All sensors were compliant with ISO 7726 accuracy requirements [16]

The measurements were carried out following a special and robust protocol designed consistently to the International Standards in the field [17] and involved the main physical variables affecting the thermal sensation [18]: 
- the air temperature at three heights: $0.1 \mathrm{~m}, 0.6 \mathrm{~m}$, $1.1 \mathrm{~m}$;

- the air velocity at three heights: $0.1 \mathrm{~m}, 0.6 \mathrm{~m}, 1.1$ $\mathrm{m}$;

- the dew point temperature at $0.6 \mathrm{~m}$;

- the six plane radiant temperatures at $0.6 \mathrm{~m}$;

- the floor temperature.

Sensors have been installed on a tripod (see figure 3) placed close to the occupant as prescribed by ISO Standard 7726 [16].

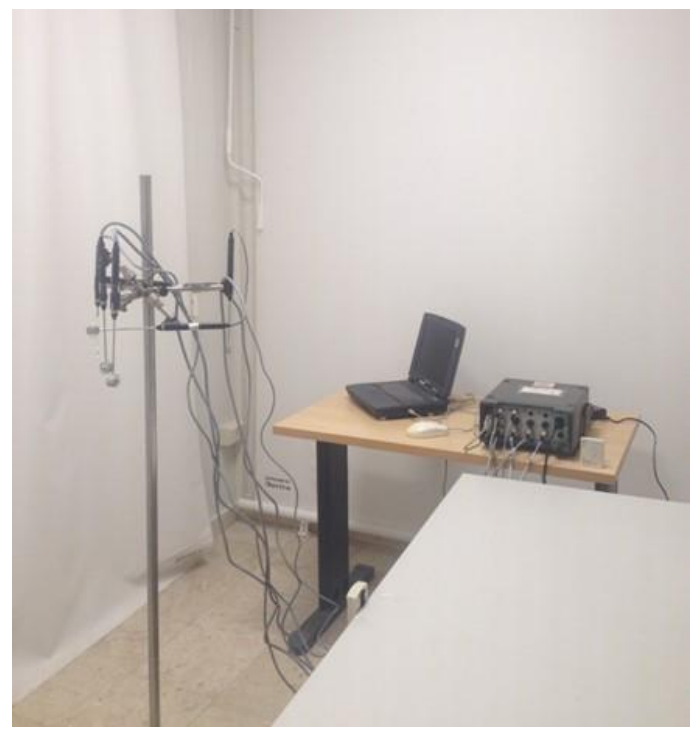

Fig. 3. Datalogger and sensors (placed near the occupied position) used for the calibration of the test room and the measurements campaign.

The calibration of the test room has been carried out by setting the HVAC system (a split unit by AERMEC) in the range from $18{ }^{\circ} \mathrm{C}$ to $25^{\circ} \mathrm{C}$ and then measuring all the physical quantities each minute for 15 minutes. The procedure has been repeated three times to verify the attainment of steady-state conditions and the homogeneity of environmental conditions was preliminarily verified by measuring the physical quantities in different positions.

Data summarized in table 3 show how microclimatic conditions of the whole experimental campaign are typical of quite uniform conditions as confirmed by the very close values of the air temperature and mean radiant temperature. In addition, the low SD values of the four physical quantities demonstrate the careful control of the microclimatic conditions with negligible effects on the subjective survey.

\subsection{Experimental runs}

\subsubsection{Experimental procedure}

81 subjects aged between 18 and 35 (41 females and 40 males) took part in the experiments. None of them had a background in the lighting field or revealed health or psychological (e.g. anxiety or stress) problems.
Subjects were led one by one in the test room (settled at $20{ }^{\circ} \mathrm{C}$ in this investigation) and they were invited to fill a short questionnaire with general information (e.g. age, height, weight, nationality, possible health problems). Then they were asked to stay inside the testroom for a time of 10 minutes to adapt to the environmental conditions. During this short period, they were also invited to play a word puzzle. This served as a distraction with respect to the surrounding environment in such a way that they would not have had memory of it in the next test.

After the subjects experienced the test room conditions, a sound signal was given to prompt them to fill a questionnaire focused on the thermal perception. After having completed the questionnaire, the subjects were invited to leave the test room for 10-15 minutes in order to change the light scene. At this point the subjects were accompanied again in the test room, and the procedures of adaptation and administration of the questionnaire were repeated.

Table 1. Summary of microclimatic parameters value recorded $0.60 \mathrm{~m}$ above the floor for a set point temperature of the test room equal to $20^{\circ} \mathrm{C}(81$ runs). $\mathrm{SD}=$ Standard Deviation.

\begin{tabular}{|l|c|c|}
\hline Quantity & MEAN & SD \\
\hline Air temperature $t_{a},{ }^{\circ} \mathrm{C}$ & 20.3 & 0.2 \\
\hline Mean radiant temperature $t_{r},{ }^{\circ} \mathrm{C}$ & 20.8 & 0.0 \\
\hline Operative temperature $t_{o},{ }^{\circ} \mathrm{C}$ & 20.6 & 0.1 \\
\hline Air velocity $v_{a}, \mathrm{~m} / \mathrm{s}$ & 0.01 & 0.00 \\
\hline Relative humidity $R H, \%$ & 53.9 & 2.7 \\
\hline
\end{tabular}

\subsubsection{Questionnaire description}

A special questionnaire designed with the assistance of a team of psychologists and doctors [19] has been administered to each interviewed and specifically adapted to make it fast to be completed.

The questionnaire consists of two sections:

- personal information. In this section subjects have to describe their clothing at the moment of the survey;

- thermal comfort. The questions of this section have been formulated in compliance with the recommendations of ISO 10551 Standard [20] and deal with the thermal status in terms of perception, evaluation and preference scale as showed in figure 4.

The questions also deal with humidity and thermal preference. A final question is focused on the possible effect of environmental conditions on the playing ability (not discussed here).

In the present investigation only the answer to the thermal perception (overall thermal state) has been considered. It is expressed in terms of a Thermal Sensation Vote (TSV) on the typical 7-point scale [18, 21] from -3 (cold) to +3 (hot). 


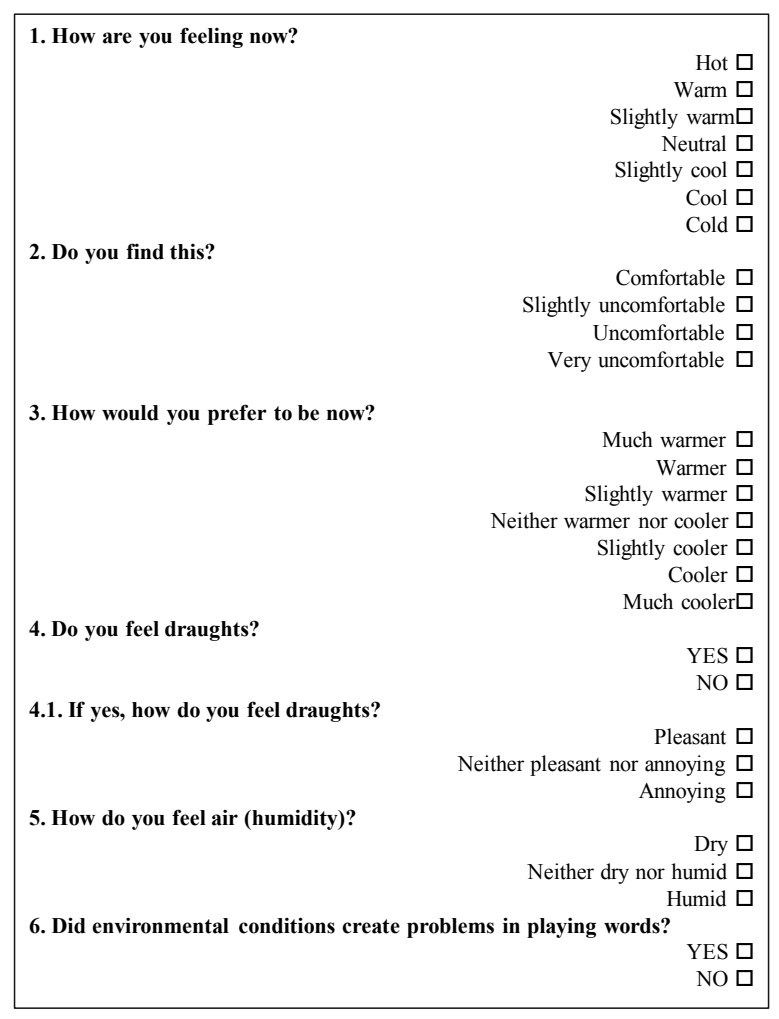

Fig. 4. The section of the questionnaire devoted to the thermal comfort assessment.

\subsubsection{Statistical analysis}

To verify the significance of the hue-heat hypothesis from subjective investigations, the well-known 2-tailed t-student test has been used [22]. In particular, by means of special Matlab functions, the following parameters were calculated:

- $\quad$ the 2- tailed Student's t-distribution $\mathrm{P}(\mathrm{T} \leq \mathrm{t})$;

- the 2-tailed inverse of the Student's t-distribution

$\mathrm{P}(\mu)$ by assuming a statistical significance $\mu=0.10$;

- the confidence 1-P(T $\leq \mathrm{t})$.

To verify that the differences among the samples were not related to the randomness, the occurrence of the condition $\mathrm{P}(\mathrm{T} \leq \mathrm{t})<\mathrm{P}(\mu)$ has been finally checked.

\subsubsection{Thermal comfort indices calculation}

To allow the calculation of the thermal comfort indices [18], personal parameters as the metabolic rate and the clothing insulation have been evaluated according to the ISO 8996 [23] and the ISO 9920 [24] Standards, respectively. The metabolic rate has been fixed at 1.3 met consistently to sedentary activities [19, 23], whereas basic clothing insulation values were evaluated from questionnaires (see table 2) and corrected by the effect of air velocity and body movement [24, 25].

Finally, the calculation of PMV and PPD indices, required for the objective assessment of overall thermal comfort conditions according to the ISO Standard 7730 [18], has been carried out from measured values by means of the TEE package $[26,27]$. This is a special software devoted to the assessment of the Thermal
Environment in agreement with the whole International Standards devoted to the Ergonomics of the Thermal Environment.

Table 2. Basic clothing insulation values with standard deviation expressed in clo $\left(1 \mathrm{clo}=0.155 \mathrm{~m}^{2} \mathrm{~K} / \mathrm{W}\right)$ measured on the investigated sample.

\begin{tabular}{|c|c|c|}
\hline Females & Males & Overall \\
\hline $0.93 \pm 0.25$ & $0.80 \pm 0.14$ & $0.86 \pm 0.20$ \\
\hline
\end{tabular}

\section{Results and discussion}

The results of the subjective investigation in terms of thermal perception are reported in tables 3 and 4 and in figure 5. In table 3 the PMV values calculated from the instrumental surveys and the real clothes worn by each interviewed have been also reported.

Data summarized in table 3 seem to confirm the hueheat hypothesis for the sample of investigated subjects, being the thermal sensation votes recorded for cool light conditions $(6000 \mathrm{~K})$ systematically lower than those observed in case of warm $(3000 \mathrm{~K})$. In addition, these differences have not to be attributed to aleatory phenomena, but are statistically significant as confirmed by the verification of the $t$-test $\mathrm{P}(\mathrm{t} \leq \mathrm{T})<\mathrm{P}(\mu=0.10)$ for the overall sample and for each gender.

Table 3. Summary of TSV from subjective investigation, comparison with PMV values obtained by the objective survey and main statistical parameters. (W) light scene at $3000 \mathrm{~K}$, (C) light scene at $6000 \mathrm{~K} . \mathrm{SD}=\mathrm{Standard}$ Deviation.

\begin{tabular}{|c|c|c|c|c|c|c|}
\hline \multirow{3}{*}{ Quantity } & \multicolumn{2}{|c|}{ Females } & \multicolumn{2}{|c|}{ Males } & \multicolumn{2}{|c|}{ Overall } \\
\hline & \multicolumn{6}{|c|}{ Light scene } \\
\hline & (W) & (C) & (W) & (C) & (W) & (C) \\
\hline Mean TSV & 0.60 & 0.23 & 0.87 & 0.41 & 0.74 & 0.32 \\
\hline SD & 1.01 & 0.73 & 0.83 & 0.82 & 0.92 & 0.78 \\
\hline PMV & \multicolumn{2}{|c|}{-0.25} & \multicolumn{2}{|c|}{-0.34} & \multicolumn{2}{|c|}{-0.32} \\
\hline SD & \multicolumn{2}{|c|}{0.37} & \multicolumn{2}{|c|}{0.23} & \multicolumn{2}{|c|}{0.30} \\
\hline \multicolumn{7}{|c|}{ t-test results } \\
\hline $\mathrm{P}(\mathrm{T} \leq \mathrm{t})$ & \multicolumn{2}{|c|}{0.0691} & \multicolumn{2}{|c|}{0.0175} & \multicolumn{2}{|c|}{0.0032} \\
\hline $\mathrm{P}(\mu=0.10)$ & \multicolumn{2}{|c|}{1.6706} & \multicolumn{2}{|c|}{1.6676} & \multicolumn{2}{|c|}{1.6567} \\
\hline Confidence & \multicolumn{2}{|c|}{$93.1 \%$} & \multicolumn{2}{|c|}{$98.3 \%$} & \multicolumn{2}{|c|}{$99.7 \%$} \\
\hline
\end{tabular}

Despite Toftum et al. [12] and similarly to what found by Wang et al. [14] our findings seem to demonstrate that CCT is associated with thermal sensation even under incipient warm discomfort conditions. Particularly, with reference to the sample as a whole, for the light scene at $3000 \mathrm{~K}$, the thermal sensation by questionnaires is typical of slightly warm conditions (mean $\mathrm{TSV}=0.74$ on the edge of class $\mathrm{C}$ comfort zone [18]) with a percentage of persons who 
voted a $\mathrm{TSV} \geq 1$ equal to $59 \%$ (see table 4 ). In the presence of cool light $(6000 \mathrm{~K})$ mean TSV decreases to 0.32 and the percentage of those who felt slightly warm or warm decreased to $40 \%$. In addition, the percentage of respondents under neutral conditions and those who felt slightly cold increased from 34 to $46 \%$ and from 5 to $14 \%$, respectively.

A reasonable explanation for the disagreement with Toftum et al.'s findings [12] could be the choice of the illuminance rate. Unlike Danish team who worked at $1000 \mathrm{~lx}$ (a common value for health care or special industrial tasks) and similarly to Wang et al. investigation [14], the present study has been carried out at 300 lux which is a typical value for some educational tasks [15].

Table 4. Percentage of persons who voted a single option to the question on the thermal sensation of the ASHRAE scale (How are you feeling now?). (W) light scene at $3000 \mathrm{~K}$, (C) light scene at $6000 \mathrm{~K}$.

\begin{tabular}{|l|r|r|r|r|r|r|}
\hline \multirow{3}{*}{ Sensation } & \multicolumn{2}{|c|}{ Females } & \multicolumn{7}{c|}{ Males } & \multicolumn{2}{c|}{ Overall } \\
\cline { 2 - 7 } & \multicolumn{6}{|c|}{ Light scene } \\
\cline { 2 - 7 } & (W) & (C) & (W) & (C) & (W) & $(\mathrm{C})$ \\
\hline cold & 0 & 0 & 0 & 0 & 0 & 0 \\
\hline cool & 3 & 0 & 0 & 0 & 1 & 0 \\
\hline $\begin{array}{l}\text { slightly } \\
\text { cool }\end{array}$ & 9 & 14 & 3 & 13 & 5 & 14 \\
\hline neutral & 34 & 51 & 33 & 41 & 34 & 46 \\
\hline $\begin{array}{l}\text { slightly } \\
\text { warm }\end{array}$ & 34 & 31 & 38 & 38 & 36 & 35 \\
\hline warm & 20 & 3 & 26 & 8 & 23 & 5 \\
\hline hot & 0 & 0 & 0 & 0 & 0 & 0 \\
\hline
\end{tabular}

According to several literature studies [12, 28, 29, 30], that seem to confirm a certain gender related perception of thermal conditions, resulting in a high sensitivity of women to low temperatures [28, 29], this investigation has revealed a more pronounced effect of colour temperature on women's thermal perception. Based upon data in table 4 , in case of warm light $54 \%$ of the women $(64 \%$ of the men) voted warm o slightly warm with $34 \%$ of the respondents under neutral conditions (33\% for men), whereas under cool light conditions the percentage of the women who voted $\mathrm{TSV} \geq 1$ decreased to $34 \%$ ( $46 \%$ in case of the men). Consequently, the percentage of the women who felt neither cold nor warm increased from 34 to $51 \%$ (from 33 to $41 \%$ in case of men).

Finally, data in table 3 highlight a certain inconsistency between the subjective investigation by questionnaires and the objective assessment carried out by means of the PMV index. Particularly, TSV values obtained by subjective analysis were systematically positive and generally consistent with comfort conditions only for cool light. To the contrary, PMV values were slightly negative and consistent with comfort levels typical of category C [18]. This is because PMV index does not account neither gender related differences nor other non-tactile stimulations as light. In addition, the standard deviation values of TSV votes were near to one point (ranging from 0.73 to 1.01 depending upon the group) revealing a significant inter-individual difference within the same group of interviewed.

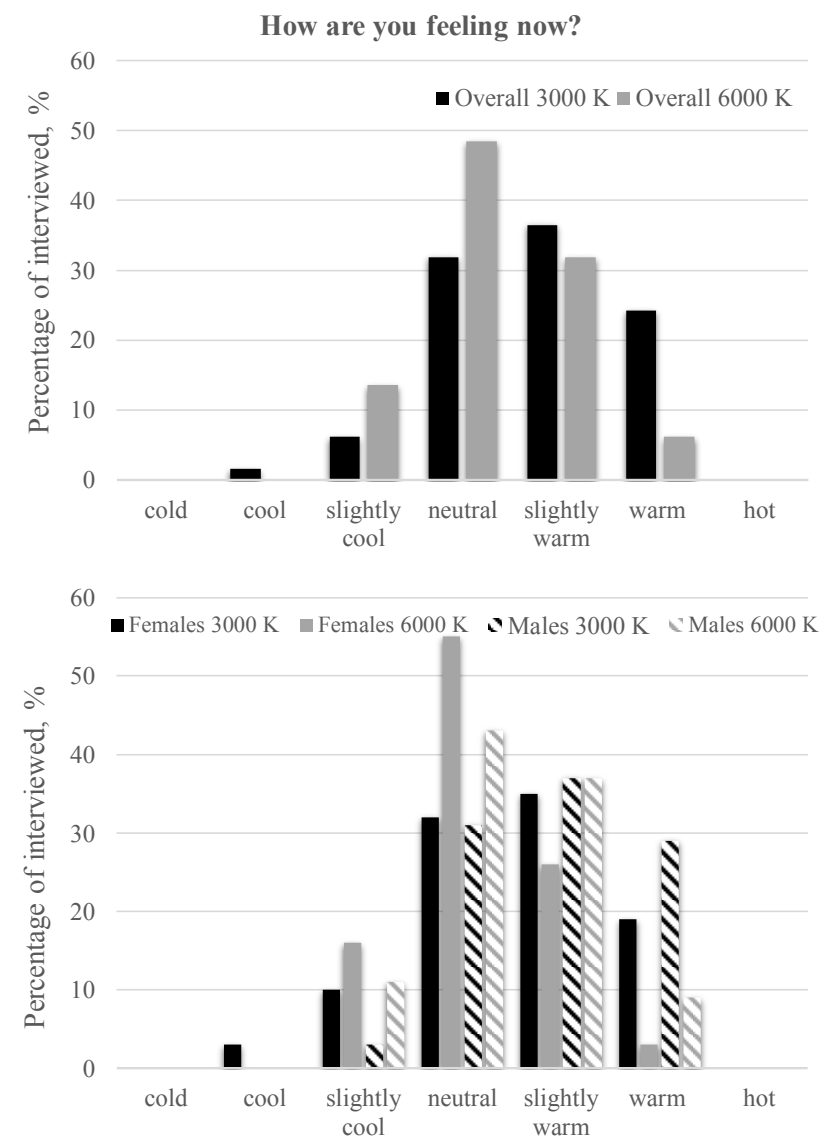

Fig. 5. Results of the subjective investigation with the two light scenes under winter condition (air temperature in the test room settled at $20^{\circ} \mathrm{C}$ ).

\section{Conclusions}

In a general context where the attainment of energy saving goals (e.g. as in nZEB) has to be consistent with high indoor environmental quality levels, it is impossible thinking to maximize a single IEQ component (e.g thermal or visual) without considering possible mutual interactions or negative effects on energy costs.

From this perspective studying the mutual interaction of the four aspects of the IEQ is a crucial need to obtain high overall comfort levels, protect the health of occupants and their productivity and avoid unbalanced design solutions resulting in negative effects on IEQ and buildings energy demand.

In this paper the hue-heat hypothesis, based on the idea that light and colours can affect the thermal perception has been investigated. Based on this assumption, changing light characteristics could help in improving thermal comfort for the occupants by operating on the set-point temperature of HVAC systems increasing warmth (cold) sensation during winter (summer). 
Based upon preliminary results obtained in a special mechanically conditioned test room provided with whitetuning LED sources we can confirm that, under winter conditions, cooler light $(6000 \mathrm{~K})$ induces a shift of the thermal sensation toward cold. The effect seems to be more pronounced in case of women whose percentage under neutral conditions has almost doubled by changing the CCT from 3000 (warm light) to $6000 \mathrm{~K}$ (cool light).

The results of this preliminary investigation will be integrated with the analysis of the answers given on the evaluation and preference scales. This is specially to verify whether the reduction of the thermal sensation votes induced by coo light is associated with higher preferred temperatures and different experienced comfort conditions. Further investigations will be also addressed to verify possible effects of lighting parameters (e.g. illuminance and/or CCT) under different microclimatic conditions (e.g. near thermal neutrality or cold discomfort also accounting for local thermal discomfort). Additional studies will be carried out on a wider and heterogeneous sample of interviewed also considering other human factors (e.g. psychological issues, stress, anxiety). Finally, further efforts will be addressed on the assessment of potential energy savings for heating and cooling obtained by operating on the CCT of the lighting system.

This research has been carried out within the "Renovation of existing buildings in NZEB vision (nearly Zero Energy Buildings)" Project of National Interest (Progetto di Ricerca di Interesse Nazionale - PRIN) funded by the Italian Ministry of Education, Universities and Research (MIUR).

We owe a special thanks to Zumtobel for the luminaires and Ranieri Impiantistica for the HVAC system.

\section{References}

1. E. Attaianese, G. Duca, Work, 41(1), 2141 (2012).

2. F.R. d'Ambrosio Alfano, B.W. Olesen, B.I. Palella, G. Riccio, Energ Buildings, 81, 326 (2014).

3. USGBC, LEED for New Construction Projects Directory, $\quad$ http://www.usgbc.org/projects/newconstruction (2013).

4. S. Mahmoud, T. Zayed, M. Fahmy, Sustain Cities Soc 44, 99 (2019).

5. European Union, Directive 2018/844/EU of The European Parliament and of the Council of 30 May 2018 amending Directive 2010/31/EU on the energy performance of buildings and Directive 2012/27/EU on energy efficiency (2018).

6. J. Andersson, A. Boerstra, D. Clements-Croome, K. Fitzner, S.O. Hanssen SO, Indoor climates and productivity in offices - REHVA guidebook no. 6 (REHVA, Brussels, 2006).
7. Y. Al Horr, M. Arif, A. Kaushik, A. Mazroei, M. Katafygiotou, E. Elsarrag, Build Environ 105, 369 (2016).

8. C.A. Bennett, P. Rey, Hum Factors 14(2), 149 (1972).

9. V. Candas, A. Dufour, J Physiol Anthropol 24(1), 33 (2005).

10. P.O. Fanger, N.O. Breum, E. Jerking, Proceedings of Symposium on Physiological requirements on the microclimate in industry and problems of their technical realizations, Prague (1975).

11. F.R. d'Ambrosio Alfano, B.W. Olesen, B.I. Palella, Energ Buildings 152, 243 (2017).

12. J. Toftum, A. Thorseth, J. Markvart, A. Logadóttir, Build Environ 143, 258 (2018).

13. G.M. Huebner, D.T. Shipworth, S. Gauthier, C. Witzel, P. Raynham, W. Chan, Energy Res Soc Sci 15, 45 (2016).

14. H. Wang, G. Liu, S. Hu, C. Liu, Energ Buildings 173, 710 (2018).

15. CEN, Light and lighting - Lighting of work places Part 1: Indoor work places. EN Standard 12464-1, Brussels (2011).

16. ISO, Ergonomics of the thermal environment Instruments for measuring physical quantities - ISO Standard 7726, Geneva (1998).

17. F.R. d'Ambrosio Alfano, E. Ianniello, C. Ziviello, $10^{\text {th }}$ International conference on air distribution in rooms, Roomvent, Helsinki (2007).

18. ISO, Ergonomics of the thermal environment Analytical determination and interpretation of thermal comfort using calculation of the PMV and PPD indices and local thermal comfort - ISO Standard 7730, Geneva (2005).

19. F.R. d'Ambrosio Alfano, E. Ianniello, B.I Palella, Build Environ 67, 129 (2013).

20. ISO, Ergonomics of the thermal environment Assessment of the influence of the thermal environment using subjective judgement scales - ISO Standard 10551, Geneva (1995). 
21. ASHRAE, Thermal environmental conditions for human occupancy - ANSI/ASHRAE Standard 55, Atlanta (2017).

22. E.P. Box, William G. Hunter, J. Stuart Hunter, Statistics for Experimenters: An Introduction to Design, Data Analysis, and Model Building, (John Wiley and Sons., New York, 1981).

23. ISO, Ergonomics of the thermal environment Determination of metabolic rate - ISO Standard 8996, Geneva (2004).

24. ISO 9920. Ergonomics of the thermal environment e estimation of the thermal insulation and evaporative resistance of a clothing ensemble - ISO Standard 9920 Geneva (2007).

25. F.R. d'Ambrosio Alfano, B.I. Palella, G. Riccio, J. Malchaire, Ann Occup Hyg 60(2), 231 (2016).

26. F.R. d'Ambrosio Alfano, B.I. Palella, G. Riccio, Enrgy Proced 101, 249 (2016).

27. F.R. d'Ambrosio Alfano, B.I. Palella, G. Riccio, J. Toftum, Int J Ind Ergonom 66, 157 (2018).

28. J. Kim, R. de Dear, C. Cândido, H. Zhang, E. Arens, Build Environ 70, 245 (2013).

29. S. Karjalainen, Indoor Air 22, 96 (2012).

30. R. Forgiarini Rupp, N. Giraldo Vásquez, R. Lamberts, Energ Buildings 105, 178 (2015). 